\title{
Poly-L-lysine Prevents Senescence and Augments Growth in Culturing Mesenchymal Stem Cells Ex Vivo
}

\author{
June Seok Heo, ${ }^{1}$ Hyun Ok Kim, ${ }^{1,2}$ Seung Yong Song, ${ }^{3}$ Dae Hyun Lew, \\ Youjeong Choi, ${ }^{1}$ and Sinyoung Kim ${ }^{2}$ \\ ${ }^{1}$ Cell Therapy Centre, Severance Hospital, Seoul 03722, Republic of Korea \\ ${ }^{2}$ Department of Laboratory Medicine, Yonsei University College of Medicine, Seoul 03722, Republic of Korea \\ ${ }^{3}$ Department of Plastic and Reconstructive Surgery, Yonsei University College of Medicine, Seoul 03722, Republic of Korea \\ Correspondence should be addressed to Sinyoung Kim; sykim@yuhs.ac
}

Received 18 March 2016; Accepted 23 May 2016

Academic Editor: Giulio Mengozzi

Copyright (C) 2016 June Seok Heo et al. This is an open access article distributed under the Creative Commons Attribution License, which permits unrestricted use, distribution, and reproduction in any medium, provided the original work is properly cited.

\begin{abstract}
Mesenchymal stem cells (MSCs) possess great therapeutic potential. Efficient in vitro expansion of MSCs is however necessary for their clinical application. The extracellular matrix (ECM) provides structural and biochemical support to the surrounding cells, and it has been used as a coating substrate for cell culture. In this study, we have aimed to improve the functionality and stemness of MSCs during culture using poly-L-lysine (PLL). Functionality of MSCs was analysed by cell cycle analysis, differentiation assay, $\beta$-galactosidase staining, and RT-PCR. Furthermore, we assessed the global gene expression profile of MSCs on uncoated and PLL-coated plates. MSCs on PLL-coated plates exhibited a faster growth rate with increased S-phase and upregulated expression of the stemness markers. In addition, their osteogenic differentiation potential was increased, and genes involved in cell adhesion, FGF-2 signalling, cell cycle, stemness, cell differentiation, and cell proliferation were upregulated, compared to that of the MSCs cultured on uncoated plates. We also confirmed that MSCs on uncoated plates expressed higher $\beta$-galactosidase than the MSCs on PLL-coated plates. We demonstrate that PLL provides favourable microenvironment for MSC culture by reversing the replicative senescence. This method will significantly contribute to effective preparation of MSCs for cellular therapy.
\end{abstract}

\section{Introduction}

The differentiation of mesenchymal stem cells (MSCs) into multiple cell lineages can be exploited as an attractive strategy for cell-based therapy and regenerative medicine [1]. MSCs can easily be obtained from various human tissue sources such as the bone marrow, cord blood, placenta, and adipose [2-5]. The clinical application of MSCs to tissue engineering has been introduced due to their numerous advantages including high expansion potential and extensive differentiation potential $[6,7]$. However, MSCs need to be expanded in vitro in order to obtain sufficient cells for clinical trials since they are extremely rare in various tissues. Unlike embryonic stem cells, adult stem cells (MSCs) have a limited lifespan and stop proliferating during in vitro culture due to replicative senescence [8].

Cellular senescence, which is morphologically characterized by an enlarged and flattened cell shape, was first described by Hayflick [9]. Cellular senescence refers to active cells that eventually enter a state of irreversible growth arrest. Moreover, replicative senescence of MSCs exhibits reduced functionality, and cellular senescence might impair the regenerative potential of MSCs [10]. Studies investigating MSC senescence are therefore crucial for successful therapeutic application of MSCs. The mechanisms underlying the cellular senescence of MSCs are still poorly understood. Studies show that replicative senescence or cellular senescence is induced by intrinsic or extrinsic environmental factors [11]. The shortening of telomeres constitutes an intrinsic factor, whereas DNA damage is considered an extrinsic factor. Specifically, oxidative stress by reactive oxygen species (ROS) is the main extrinsic factor that induces senescence [12]. Cellular senescence is a complex process, and its molecular mechanisms are unknown. A number of studies demonstrated that hypoxia is beneficial to the senescence of MSC; however the precise understanding mechanism is not clear [13-15]. It was also 
shown that inhibition of the p16 tumour suppressor gene delays growth arrest and therefore senescence of MSC [16]. Additionally, Abedin and King showed that FGF-2 suppresses the cellular senescence of human MSCs [17]. It is hard to preserve the important characteristics such as proliferation capacity and stemness of MSCs the inadequate cultivating microenvironment in vitro. Therefore, establishing an optimized culture condition that delays the senescence of MSCs is imperative.

MSCs naturally reside in a specialized niche in vivo, which mainly consists of the extracellular matrix (ECM). The ECM provides structural and biochemical support to the cells and has various other functions including cell adhesion, cell to cell communication, and differentiation $[17,18]$. Poly-Llysine (PLL) of extracellular matrix proteins is a small natural homopolymer of the essential amino acid L-lysine that is used to coat culture substrates. PLL functions as an attachment factor that enhances cell adherence due to its strong affinity for proteins and electrostatic interactions between the positive charges on the PLL molecule and the negative charges on the cell membrane $[19,20]$. Park et al. showed that PLL increases the ex vivo expansion and erythroid differentiation of human hematopoietic stem cells [21]. It was also reported that PLL promoted neural progenitor cell function, and it is commonly used for MSC differentiation into neural lineages [22]. Recent studies suggest that neuroectodermal cells can generate MSCs, and they may arise in the neural crest, which is derived from embryonic neuroectoderm [23, 24]. These studies emphasized the interesting possibility that PLL could provide a favourable environment for MSC culture in vitro. We therefore hypothesized that PLL would be beneficial for MSC culture expansion and would preserve MSC properties in vitro. In this study, PLL-coated plates were used for MSC culture expansion. To the best of our knowledge, this study is the first to compare genome-wide expression profiles of MSCs cultured on PLL-coated plates with MSCs cultured on uncoated plates. In addition, we compared and analysed properties of MSCs cultured on PLL-coated plates with uncoated plates. The PLL-coated surface provided an excellent environment that improved the stemness of MSCs and delayed their senescence through upregulation of genes involved in cell adhesion, FGF-2 signaling, cell cycle, stemness, cell differentiation, and proliferation. This method could be useful for in vitro expansion of highly functional MSCs for cell-based therapeutic applications.

\section{Materials and Methods}

2.1. Reagents. Dulbecco's Modified Eagle Medium (DMEM), $\alpha \mathrm{MEM}$, foetal bovine serum (FBS), penicillin/streptomycin $(\mathrm{P} / \mathrm{S}), 0.4 \%$ trypan blue stain, and TRIzol were obtained from Gibco (Invitrogen, Carlsbad, CA, USA). Mesenchymal stem cell growth medium (MSCGM), osteogenic differentiation medium, adipogenic differentiation medium, and chondrocyte differentiation medium were obtained from Cambrex (Lonza, Allendale, NJ, USA). Poly-L-lysine (PLL) and propidium iodide (PI) were purchased from SigmaAldrich (St. Louis, MO, USA). The senescence detection kit was obtained from BioVision Inc. Oligonucleotides for polymerase chain reaction (PCR), reverse transcription, and CDNA were synthesized by Bioneer (Bioneer Corporation, Daejeon, Korea). Silver nitrate, oil red O, and safranin O for differentiation staining were purchased from Sigma-Aldrich.

2.2. Cell Culture. MSCs were isolated from human bone marrow as previously described [25]. Cells after informed consent were collected from healthy three donors with approval from the Research Ethics Committee of Severance Hospital (Approval number 4-2014-0650). Primary cells of passage 0 were cultured and maintained in low glucose DMEM (DMEM-LG) supplemented with 10\% FBS and 1\% $\mathrm{P} / \mathrm{S}$ at $37^{\circ} \mathrm{C}$ in $5 \% \mathrm{CO}_{2}$. Cells were harvested using $0.05 \%$ trypsin/EDTA (Invitrogen) when they reached 80-90\% confluence for further experiment. Harvested $2 \times 10^{4}$ cells/well in 12 -well plates were replated in $0.01 \%$ PLL-coated or uncoated plates for all experiments.

2.3. Flow Cytometry Analysis. For immunophenotyping, MSCs were stained with fluorescein isothiocyanate- (FITC-) or phycoerythrin- (PE-) conjugated monoclonal antibodies: CD14-FITC, CD29-FITC, CD31-PE, CD34-FITC, CD44-PE, CD45-PE, CD73-PE, CD90-FITC, CD105-PE, and CD106FITC (all from BD Pharmingen, San Diego, CA, USA). Additionally, FITC- and PE-conjugated isotype controls were used as negative controls. Briefly, cultured MSCs were harvested and stained with the antibodies for $20 \mathrm{~min}$ at $4^{\circ} \mathrm{C}$. Subsequently, the stained cells were washed with phosphate buffered saline (PBS) and fixed with $1 \%$ paraformaldehyde (Biosesang, Seongnam, Korea). The cells were analysed using a flow cytometer (Cytomics Flow Cytometer; Beckman Coulter, Fullerton, CA, USA).

2.4. Growth Characteristics. For analysis of cell proliferation, MSCs were plated at a density of $2 \times 10^{4}$ per well in uncoated or PLL-coated 12-well plates (Corning Inc., Corning 07200-81, NY, USA) in MSC culture medium. Cultures were maintained for 5 days and then harvested for cell counting on days 3,4 , and 5 . The proliferation rate of cells was determined using the trypan blue exclusion method. The population doubling time was calculated as the cumulative number of serial cells passaging until the cells reached senescence [26]. At passage 7, cells were photographed.

2.5. Cell Cycle Analysis. The cultured MSCs at passage 7 were removed from uncoated and PLL-coated plates. Harvested cells washed with PBS and fixed with cold $70 \%$ ethanol while minimizing clumping. After $30 \mathrm{~min}$ at $4^{\circ} \mathrm{C}$, the cells were washed with PBS and stained with propidium iodide. Propidium iodide fluorescence was then examined using the Cytomics Flow Cytometer (Beckman Coulter).

2.6. $\beta$-Galactosidase Staining. $\beta$-galactosidase staining was performed using the senescence associated $\beta$-galactosidase staining kit (BioVision Inc.), according to the manufacturer's instructions. Briefly, passage 7 MSCs cultured on uncoated and PLL-coated plates were washed with PBS and fixed with $4 \%$ paraformaldehyde at room temperature. After washing 
TABle 1: Primer sequences.

\begin{tabular}{|c|c|c|c|}
\hline Gene & Primer sequence $\left(5^{\prime}-3^{\prime}\right)$ & $\begin{array}{c}\text { Annealing } \\
\text { temperature }\left({ }^{\circ} \mathrm{C}\right)\end{array}$ & $\begin{array}{l}\text { Product } \\
\text { size (bp) }\end{array}$ \\
\hline $\mathrm{p} 16^{\mathrm{INK4a}}$ & $\begin{array}{l}\text { Forward: CGAATAGTTACGGTCGGAGG } \\
\text { Reverse: GCATGGTTACTGCCTCTGGT }\end{array}$ & 62 & 309 \\
\hline p21 ${ }^{\text {Cipl }}$ & $\begin{array}{l}\text { Forward: GCGATGGAACTTCGACTTTG } \\
\text { Reverse: CGTTTTCGACCCTGAGAGAGTC }\end{array}$ & 60 & 285 \\
\hline SH3 (CD73) & $\begin{array}{l}\text { Forward: TATTGCACTGGGACATTCGGGT } \\
\text { Reverse: GGTTGCCCATGTTGCATTCTCT }\end{array}$ & 62 & 443 \\
\hline SH2 (CD105) & $\begin{array}{l}\text { Forward: CATCCTTGAAGTCCATGTCCTCTT } \\
\text { Reverse: GCCAGGTGCCATTTTGCTT }\end{array}$ & 62 & 95 \\
\hline VCAM-1 (CD106) & $\begin{array}{l}\text { Forward: GCTTTCCTGCTCCGAAAATCCT } \\
\text { Reverse: AACTGGGCCTTTCGGATGGTAT }\end{array}$ & 62 & 367 \\
\hline Oct4 & $\begin{array}{l}\text { Forward: GACAACAATGAGAACCTTCAGGAGA } \\
\text { Reverse: TTCTGGCGCCGGTTACAGAACCA }\end{array}$ & 62 & 218 \\
\hline Sox 2 & $\begin{array}{l}\text { Forward: AACCAAGACGCTCATGAAGAAG } \\
\text { Reverse: GCGAGTAGGACATGCTGTAGGT }\end{array}$ & 62 & 341 \\
\hline Nanog & $\begin{array}{l}\text { Forward: ATAGCAATGGTGTGACGCAG } \\
\text { Reverse: GATTGTTCCAGGATTGGGTG }\end{array}$ & 62 & 219 \\
\hline GAPDH & $\begin{array}{l}\text { Forward: GTGGTCTCCTCTGACTTCAACA } \\
\text { Reverse: CTCTTCCTCTTGTGCTCTTGCT }\end{array}$ & 62 & 210 \\
\hline
\end{tabular}

with PBS, cells were incubated with senescence-associated $\beta$ galactosidase (SA- $\beta$-gal) staining solution for $24 \mathrm{~h}$ at $37^{\circ} \mathrm{C}$. The number of $\beta$-galactosidase positive cells (blue colour) was evaluated under a light microscope (Olympus-IX71), as an indicator of the number of senescent cells.

2.7. Reverse Transcription PCR (RT-PCR). Total RNA was prepared using TRIzol reagent, and cDNA was synthesized using transcriptase II (Invitrogen). RT-PCR was performed with PCR primers under the conditions listed in Table 1 (Bioneer). Glyceraldehyde 3-phosphate dehydrogenase (GAPDH) was used as an internal standard. The signal intensity of the product was normalized to its respective GAPDH signal intensity.

2.8. Differentiation Assay. To assess the differentiation potential of MSCs, cells were seeded at $7 \times 10^{4} /$ well in 12 -well plates for the induction of osteogenesis and chondrogenesis and 1.5 $\times 10^{5} /$ well in 12 -well plates for inducing adipogenesis. For differentiation, primary and passage 7 MSCs were maintained for 14 days in osteogenic, adipogenic, or chondrogenic differentiation medium (Lonza). For chondrogenesis, cells were treated with $10 \mathrm{ng} / \mathrm{mL}$ TGF- (transforming growth factor-) $\beta 3$ (Lonza). After induction, Von Kossa staining was applied to analyse osteogenic differentiation, and calcium content was evaluated using the calcium (CPC) liquicolor kit (Stanbio Laboratory, Boerne, USA), based on a previously reported method [27]. Briefly, the cells were washed with PBS and treated $0.5 \mathrm{~N} \mathrm{HCl}$. After shaking for $3 \mathrm{~h}$ with an orbital shaker, the supernatant was transferred to a new tube for analysis. Ortho-cresolphthalein complexone (OCPC) was added to the sample, and absorbance was detected at $550 \mathrm{~nm}$. After adipogenic differentiation, lipid droplets were detected by oil red $\mathrm{O}$ staining, and absorbance was measured at $500 \mathrm{~nm}$ after destaining with isopropanol for $30 \mathrm{~min}$ for quantitative analysis according to the previously reported method [27]. To evaluate chondrogenesis, cells were stained with safranin $\mathrm{O}$ solution, and the absorbance of sulphated glycosaminoglycan was detected at $656 \mathrm{~nm}$ using the Blyscan assay kit (Biocolor Ltd.) for quantitative analysis. Briefly, the supernatant of each sample was mixed with DMMB dye and reagents according to the manufacturer's protocols and reference [28]. Experiments were performed in triplicate.

2.9. Human Genome Microarray. The synthesis of target cRNA probes and hybridization were performed using Agilent's Low RNA Input Linear Amplification kit (Agilent Technology, USA), according to the manufacturer's instructions. Briefly, $1 \mu \mathrm{g}$ of total RNA and T7 promoter primers were mixed and incubated at $65^{\circ} \mathrm{C}$ for $10 \mathrm{~min}$. The cDNA master mix (5x first strand buffer, $0.1 \mathrm{M}$ DTT, $10 \mathrm{mM}$ dNTP mix, RNase-Out, and MMLV-RT) was prepared and added to the reaction mix. The samples were incubated at $40^{\circ} \mathrm{C}$ for $2 \mathrm{~h}$ and were then incubated at $65^{\circ} \mathrm{C}$ for $15 \mathrm{~min}$ to terminate RT and dsDNA synthesis. The transcription master mix was prepared according to the manufacturer's protocol $(4 \mathrm{x}$ transcription buffer, 0.1 M DTT, NTP mix, 50\% PEG, RNase-Out, inorganic pyrophosphatase, T7-RNA polymerase, and cyanine 3/5CTP). Transcription of dsDNA was performed by adding the transcription master mix to dsDNA reaction samples and incubating at $40^{\circ} \mathrm{C}$ for $2 \mathrm{~h}$. Amplified and labelled cRNA was purified using the cRNA Cleanup Module (Agilent Technology), according to the manufacturer's protocol. The labelled cRNA target was quantified using a ND-1000 spectrophotometer (NanoDrop Technologies, Inc., Wilmington, $\mathrm{DE})$. After checking the labelling efficiency, fragmentation of cRNA was performed by adding $10 \mathrm{x}$ blocking agent and $25 \mathrm{x}$ fragmentation buffer and incubating at $60^{\circ} \mathrm{C}$ for $30 \mathrm{~min}$. The 
fragmented cRNA was resuspended with $2 \mathrm{x}$ hybridization buffer and directly pipetted onto assembled Agilent's Human Oligo Microarray $(44 \mathrm{~K})$. The arrays hybridized at $65^{\circ} \mathrm{C}$ for $17 \mathrm{~h}$ using an Agilent hybridization oven (Agilent Technology, USA). The hybridized microarrays were washed, according to the manufacturer's washing protocol (Agilent Technology, USA).

2.10. Data Acquisition and Analysis. All data normalization and selection of differentially expressed genes were performed using GeneSpringGX 7.3 (Agilent Technology, USA). The averages of normalized ratios were calculated by dividing the average normalized signal channel intensity by the average normalized control channel intensity. Functional annotation of genes was performed according to the Gene Ontology ${ }^{\mathrm{TM}}$ Consortium (http://www.geneontology.org/index .shtml) by GeneSpringGX 7.3. Gene classification was based on searches of the BioCarta (http://www.biocarta.com/), GenMAPP (http://www.genmapp.org/), DAVID (http:// david.abcc.ncifcrf.gov/), and Medline databases (http://www .ncbi.nlm.nih.gov/).

2.11. Statistical Analysis. Statistical analysis was performed using Student's $t$-test. Quantitative data are expressed as means \pm SD. Differences are considered statistically significant at $p<0.05$.

\section{Results}

3.1. Characterization of Cultured MSCs. MSCs were isolated and cultured from human bone marrow of three different donors. Cultured MSCs displayed a fibroblast-like morphology, and they were differentiated into osteocyte, chondrocyte, and adipocyte under proper conditions (Figure 1(a)). For immunophenotyping of cultured MSCs, MSCs derived from different donors were analysed by flow cytometry. Figure 1(b) shows that MSCs were positive for MSC markers, including CD29, CD44, CD73, CD90, and CD105, whereas MSCs were negative for CD14, CD31, CD34, CD45, and CD106 known as hematopoietic and endothelial markers. The results of flow cytometry demonstrate that the cultured cells were typical MSCs.

3.2. Growth Kinetics of Cultured MSCs on Uncoated and PLL-Coated Plates. To determine the effect of PLL on in vitro culture of MSCs, we compared the proliferation activity of MSCs cultured on uncoated and PLL-coated plates. The optimal concentration of $0.01 \%$ PLL used for this study was determined empirically, since we observed that high concentrations greater than $0.01 \%$ hindered MSC adhesion and spread (data not shown). Bone marrow-derived MSCs at passage 3 were cultured for 5 days to determine whether PLL stimulates MSC proliferation in the short-term culture. The numbers of harvested cells at days 3, 4, and 5 were measured using the trypan blue exclusion method. An increase in cell numbers was detected in MSCs cultured on PLL-coated plates compared to cells grown in the absence of PLL-coating (Figure 1(c)).
3.3. PLL Suppressed MSC Replicative Senescence. Passage 7 MSCs cultured in DMEM on uncoated plates displayed the typical phenomenon of replicative senescence with morphological abnormalities (Figure 2(a)). MSCs are typically cultivated in DMEM-LG containing 10\% FBS and 1\% P/S. Additionally, $\alpha \mathrm{MEM}$ and mesenchymal stem cell growth medium (MSCGM) are also used for MSC culture. MSCGM is a known specific medium for mesenchymal stem cell growth. To investigate morphological changes of replicative senescence of MSCs, cells were replated in $\alpha$ MEM and MSCGM with DMEM. MSCs grown in $\alpha$ MEM and MSCGM exhibited similar morphological patterns including cell aggregation as MSCs grown in DMEM (data not shown). Senescent cells were subsequently seeded on uncoated and PLL-coated plates to determine whether PLL could induce any changes during culture. Surprisingly, MSCs seeded on uncoated plates maintained an aggregated phenotype with growth arrest, whereas cells on the PLL-coated plates demonstrated an increased growth rate without aggregation (Figure 2(a)). The population doubling time of MSCs cultured on PLL-coated plates was decreased compared with that of MSCs on uncoated plates in culture (Figure 2(a)). Additionally, MSCs cultured on uncoated plates did not demonstrate further growth; however MSCs cultured on PLL-coated plates reached 100\% confluence within several days. Furthermore, to examine whether PLL increased the S-phase, cell cycle analysis was carried out using flow cytometry. PLL increased the Sphase of MSCs compared to MSCs cultured in the absence of PLL (Figure 2(b)). We next investigated whether PLL suppressed MSC senescence. MSCs cultured on uncoated and PLL-coated plates were stained with $\beta$-galactosidase after the typical phenomenon of senescence was observed. MSCs cultured on uncoated plates showed a significant increase in the percentage of $\beta$-galactosidase positive cells compared to cells cultured on PLL-coated plates (Figure 2(c)).

\subsection{PLL Induced Stemness Markers and Inhibited Senescence} Related Genes. The gene expressions of known MSC markers CD73, CD105, and CD106 in MSCs at passage 7 showing a senescent phenotype cultured on uncoated and PLL-coated plates were analysed using RT-PCR analysis. All MSCs, regardless of cell culture conditions, were positive for CD105 and CD106 (Figure 3(a)). Importantly, very low levels of CD73 (ecto- $5^{\prime}$-nucleotidase), a MSC specific marker, were detected in senescent MSCs cultured on uncoated plates, whereas it was distinctly expressed in MSCs cultured on PLL-coated plates (Figure 3(a)). Oct4, Nanog, and Sox2 that regulate the maintenance of the pluripotency have been purported to play a similar role also in mesenchymal stem cells $[29,30]$. To determine whether stemness was affected by PLL, we investigated the gene expression levels of stemness markers such as Oct4, Sox2, and Nanog. Oct4 was undetectable in all MSCs regardless of culture conditions. However Sox2 and Nanog were upregulated in MSCs cultured on PLL-coated plates compared to senescent MSCs cultured on uncoated plates (Figure 3(b)). These results indicate that MSC and stemness markers were affected by PLL. In addition, to confirm whether PLL affected cell proliferation, $\mathrm{p} 16^{\mathrm{INK} 4 \mathrm{a}}$ and 


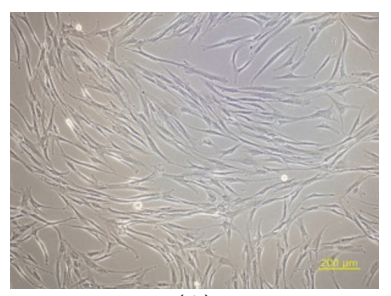

(A)

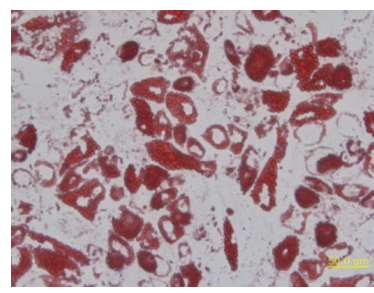

(C)

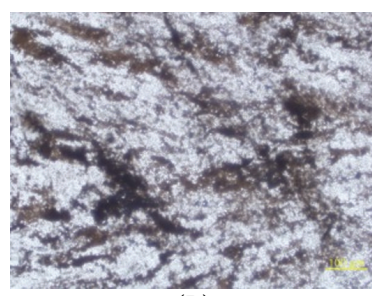

(B)

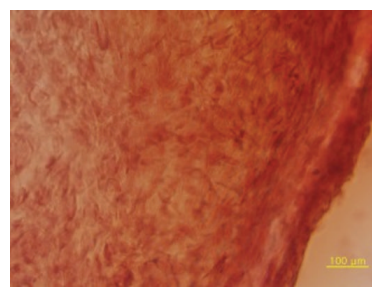

(D)

(a)
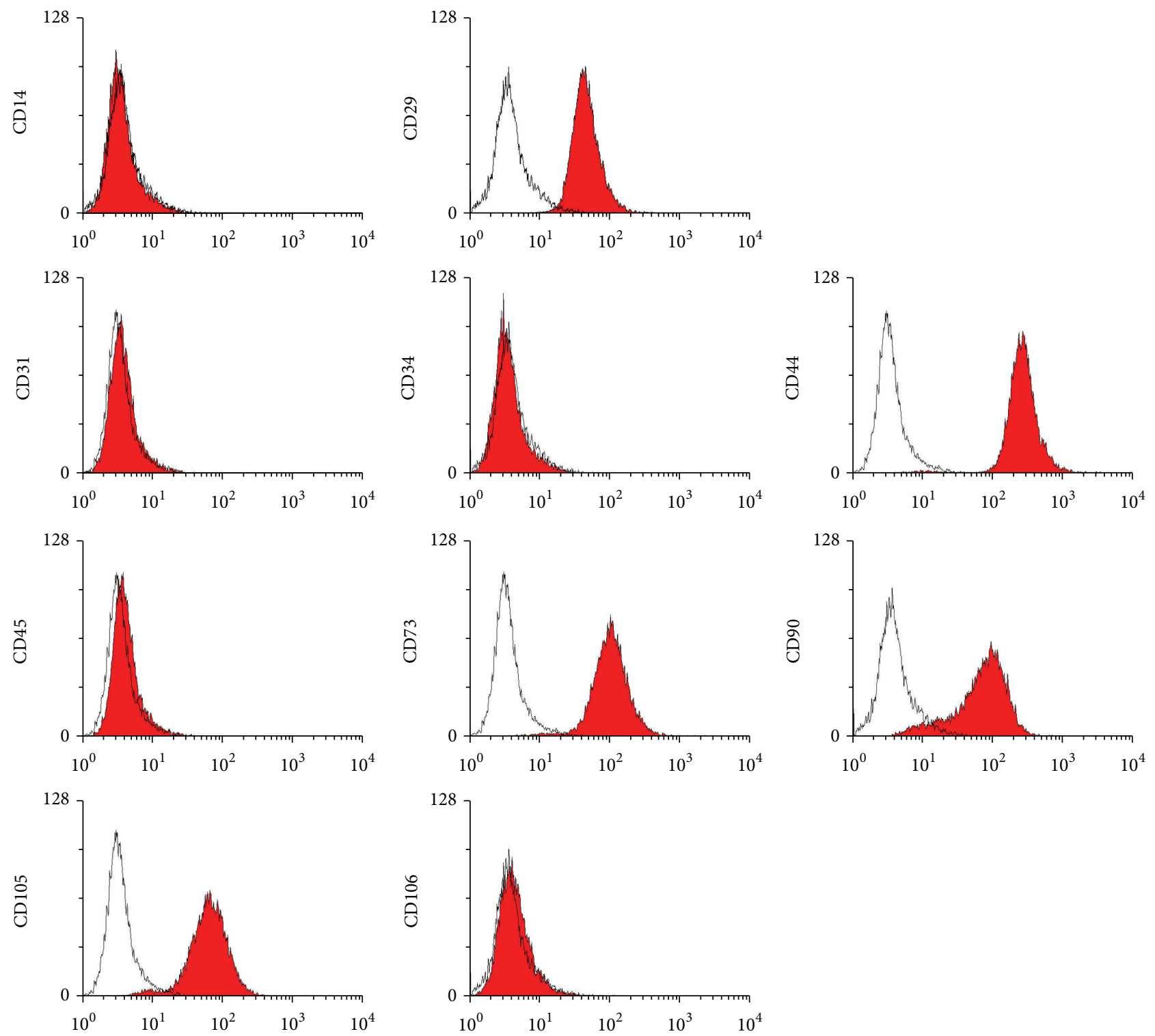

(b)

FIgURE 1: Continued. 


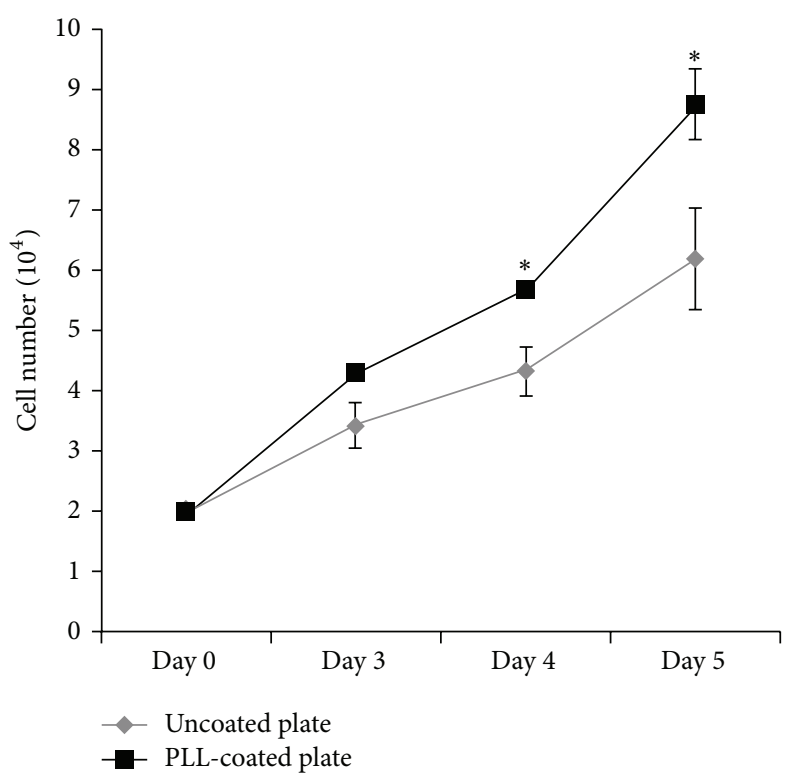

(c)

FIgURE 1: Characteristics and short-term culture of MSCs. (a) Cell morphology was observed under phase-contrast microscopy ((A) magnification: 100x) and differentiation potential was evaluated by Von Kossa, oil red $\mathrm{O}$, and safranin $\mathrm{O}$ staining ((B) osteogenesismagnification: 200x, (C) adipogenesis-magnification: 400x; (D) chondrogenesis-magnification: 200x). (b) The immunophenotype of bone marrow-derived MSCs. Flow cytometry histograms show that cultured MSCs were positive CD29, CD44, CD73, CD90, and CD105. These results show representative histograms of cultured MSCs. (c) Proliferative activity of cultured MSCs. MSCs were cultured on uncoated or poly-L-lysine- (PLL-) coated plates for 5 days. The number of harvested cells was measured by trypan blue staining. The data represent the mean \pm standard deviation of three independent experiments $(n=3) .{ }^{*} p<0.05$.

p21 ${ }^{\text {Cip1 }}$ genes associated senescence were analysed by RTPCR. As shown in Figure 3(c), the mRNA expression levels of $\mathrm{p} 16^{\mathrm{INK} 4 \mathrm{a}}$ and $\mathrm{p} 21^{\mathrm{Cip} 1}$ were decreased in cells cultured on PLL-coated plates compared to the cells on uncoated plates. In particular, the decreasing of p21 is statistically significant in passage 7 of PLL-coated plate (Figure 3(c)). These results demonstrate that senescent MSCs can be cultured normally on PLL-coated plates and that PLL can inhibit MSCreplicative senescence.

\subsection{Differentiation Potential of MSCs Cultured on PLL-Coated} Plates. To assess the differentiation potential of MSCs, cells at passage 7 showing a senescent phenotype were cultured and induced to differentiate to osteocytes, adipocytes, and chondrocytes in specific differentiation media. Von Kossa staining was used to detect calcium-containing mineralized nodules indicating osteogenic induction. The results demonstrated that MSCs cultured on PLL-coated plates showed higher amounts of Von Kossa staining compared to cells on uncoated plates, and MSCs cultured on PLL-coated plates had higher calcium accumulation compared to cells on uncoated plates in the calcium content assay (Figure 4(a)). Adipogenic differentiation was analysed by oil red O staining. Both MSCs cultured on uncoated and PLL-coated plates showed lipid droplet formation, and the absorbance value for oil red $\mathrm{O}$ staining was similar between the two culture conditions (Figure 4(b)). The chondrogenic differentiation potential of MSCs was assessed using safranin $O$ staining. Similar to the results of adipogenic differentiation, both MSCs had similar chondrogenic differentiation capacity, as sulphated glycosaminoglycan content was also similar between MSCs cultured under both conditions (Figure 4(c)).

3.6. Gene Expression Profiles. Genome-wide expression profiles of MSCs were analysed by human genome microarray. We analysed the expression patterns of senescent MSCs of the same donor cultured on uncoated and PLL-coated plates. The most significant differentially expressed genes are summarized in Tables 2 and 3. Differentially expressed genes (>twofold) in MSCs cultured on PLL and uncoated plates were sorted into 8 categories according to function: cell adhesion, FGF-2 signalling, cell cycle, oxidative stress, tumorigenicity, stemness, cell differentiation, and cell proliferation.

Upregulated genes included the following: calcium channel, voltage-dependent, L type, alpha $1 \mathrm{C}$ subunit (CACNA1C), which may play a role in the differentiation of stem cells [31]; delta-like 2 homolog (DLK2), a modulator of adipogenesis [32]; nuclear assembly factor 1 homolog (NAF1), which is required for telomerase function [33]; centromere protein I (CENPI), which is essential for mitosis [34]; apelin (APLN) that attenuates oxidative stress [35]; actinin, alpha 2 (ACTN2), which is involved in maintaining the cell spreading and motility [36]; ciliary neurotrophic factor receptor (CNTFR), which acts on neuronal populations in the developing and mature brain [37]; lethal giant larvae homolog 2 (LLGL2), 
TABLE 2: Upregulated genes (>twofold) in MSCs on uncoated and poly-L-lysine- (PLL-) coated plates.

\begin{tabular}{|c|c|c|c|}
\hline Gene name & Description & NCBI & $\mathrm{PLL} / \mathrm{UN}$ \\
\hline $\begin{array}{l}\text { Calcium channel, voltage-dependent, L } \\
\text { type, alpha } 1 \mathrm{C} \text { subunit }\end{array}$ & $\begin{array}{l}\text { Homo sapiens calcium channel, voltage-dependent, L } \\
\text { type, alpha 1C subunit (CACNA1C), transcript }\end{array}$ & NM_001129827 & 16.55 \\
\hline Delta-like 2 homolog (Drosophila) & $\begin{array}{l}\text { Homo sapiens delta-like } 2 \text { homolog (Drosophila) } \\
\text { (DLK2), transcript variant } 2\end{array}$ & NM_206539 & 10.97 \\
\hline $\begin{array}{l}\text { Nuclear assembly factor } 1 \text { homolog }(S . \\
\text { cerevisiae) }\end{array}$ & $\begin{array}{l}\text { Homo sapiens nuclear assembly factor } 1 \text { homolog }(S . \\
\text { cerevisiae) (NAF1), transcript variant } 1\end{array}$ & NM_138386 & 3.82 \\
\hline Centromere protein I & Homo sapiens centromere protein I (CENPI) & NM_006733 & 3.15 \\
\hline Apelin & Homo sapiens apelin (APLN) & NM_017413 & 3.07 \\
\hline Actinin, alpha 2 & Homo sapiens actinin, alpha 2 (ACTN2) & NM_001103 & 2.89 \\
\hline Ciliary neurotrophic factor receptor & $\begin{array}{l}\text { Homo sapiens ciliary neurotrophic factor receptor } \\
\text { (CNTFR), transcript variant } 1\end{array}$ & NM_147164 & 2.84 \\
\hline $\begin{array}{l}\text { Lethal giant larvae homolog } 2 \\
\text { (Drosophila) }\end{array}$ & $\begin{array}{l}\text { Homo sapiens lethal giant larvae homolog } 2 \\
\text { (Drosophila) (LLGL2), transcript variant } 3\end{array}$ & NM_001031803 & 2.43 \\
\hline E2F transcription factor 8 & Homo sapiens E2F transcription factor 8 (E2F8) & NM_024680 & 2.23 \\
\hline Tyrosine kinase, nonreceptor, 2 & $\begin{array}{l}\text { Homo sapiens tyrosine kinase, nonreceptor, } 2 \text { (TNK2), } \\
\text { transcript variant } 2\end{array}$ & NM_001010938 & 2.20 \\
\hline Inhibin, beta B & Homo sapiens inhibin, beta B (INHBB) & NM_002193 & 2.07 \\
\hline
\end{tabular}

TABLE 3: Downregulated genes (>twofold) in MSCs on uncoated and poly-L-lysine- (PLL-) coated plates.

\begin{tabular}{llc}
\hline Gene name & Description & NCBI \\
\hline $\begin{array}{l}\text { Hairy/enhancer-of-split related with } \\
\text { YRPW motif 1 } \\
\text { Thrombospondin 2 }\end{array}$ & $\begin{array}{l}\text { Homo sapiens hairy/enhancer-of-split related to YRPW } \\
\text { motif 1 (HEY1), transcript variant 2 }\end{array}$ & NM_001040708 \\
Leucine rich repeat containing 17 & $\begin{array}{l}\text { Homo sapiens thrombospondin 2 (THBS2) } \\
\text { Homo sapiens leucine rich repeat containing 17 } \\
\text { (LRRC17), transcript variant 2 }\end{array}$ & NM_003247 \\
Collagen, type XI, alpha 1 & $\begin{array}{l}\text { Homo sapiens collagen, type XI, alpha 1 (COL11A1), } \\
\text { transcript variant B }\end{array}$ & NM_005824 \\
$\begin{array}{l}\text { Chitinase 3-like 1 (cartilage } \\
\text { glycoprotein-39) }\end{array}$ & $\begin{array}{l}\text { Homo sapiens chitinase 3-like 1 (cartilage } \\
\text { glycoprotein-39) (CHI3L1) }\end{array}$ & NM_40629 \\
$\begin{array}{l}\text { Sulfatase 2 } \\
\text { Neurotrophic tyrosine kinase, receptor, } \\
\text { type 2 }\end{array}$ & $\begin{array}{l}\text { Homo sapiens sulfatase 2 (SULF2), transcript variant 1 } \\
\text { type 2 (NTRK2), transcript variant } c\end{array}$ & NM_018837 \\
\hline
\end{tabular}

involved in normal cell division [38]; E2F transcription factor 8 (E2F8), which plays an important role in the S-phase of the cell cycle [39]; tyrosine kinase, nonreceptor, 2 (TNK2), which inhibits the GTPase activity of p21 [40]; inhibin beta B $(I N H B B)$, which is involved in self-renewal of stem cells [41].

Downregulated genes included the following: hairy/ enhancer-of-split related to YRPW motif 1 (HEY1), a tumour specific gene [42]; thrombospondin 2 (THBS2), which mediates focal adhesion disassembly [43]; leucine rich repeat containing 17 ( $L R R C 17$ ), a known negative regulator of osteogenesis [44]; collagen, type XI, alpha 1 (COL11A1), which is expressed in tumour cell lines [45]; chitinase 3-like 1 (cartilage glycoprotein-39, CHI3L1), which is involved in oxidative stress [46]; sulphates 2 (SULF2), which is upregulated in cancer $[47,48]$; neurotrophic tyrosine kinase, receptor, type 2 (NTRK2), which stimulates focal adhesion disassembly and is involved in cancer $[49,50]$.

\section{Discussion}

Adult stem cells (MSCs) have many advantages, such as being less tumorigenic, and they do not trigger immune rejection.
MSCs thus hold significant promise for future use in stem cell therapy and tissue engineering. However, there are also disadvantages that currently limit their clinical application. MSCs exist in low quantity from a variety of sources, and it is hard to culture them in vitro because they are sensitive to external stimuli and readily enter a state of replicative senescence. The culture and expansion of a large amount of MSCs from primary sources are very important for their successful clinical application. Therefore, the development of an easy and innovative method for cultivating MSCs is critical.

Generally, cells are exposed to complex and highly structured microenvironments regulated by multiple biophysical and biochemical factors such as soluble factors and ECM in vivo [51]. The fate of MSCs is controlled by cell to cell and cell to ECM interactions [52]. Similarly, in vitro culture conditions have a significant impact on the fate of MSCs with changes in gene and protein expression profiles. ECM proteins constitute a microenvironment that provides structural support and attachment to the cells and offer essential communication between cells and their surrounding environment [53]. In this study, we applied a 


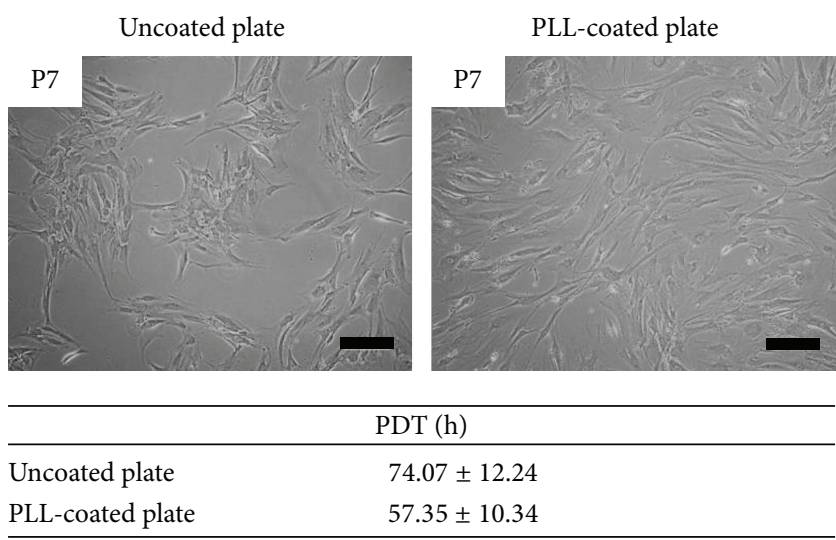

(a)
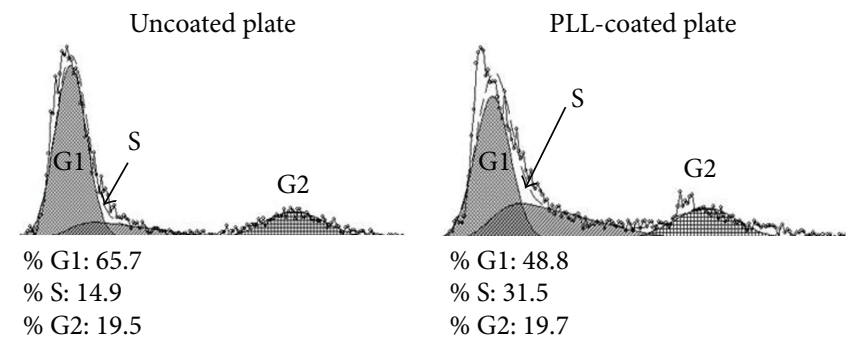

(b)
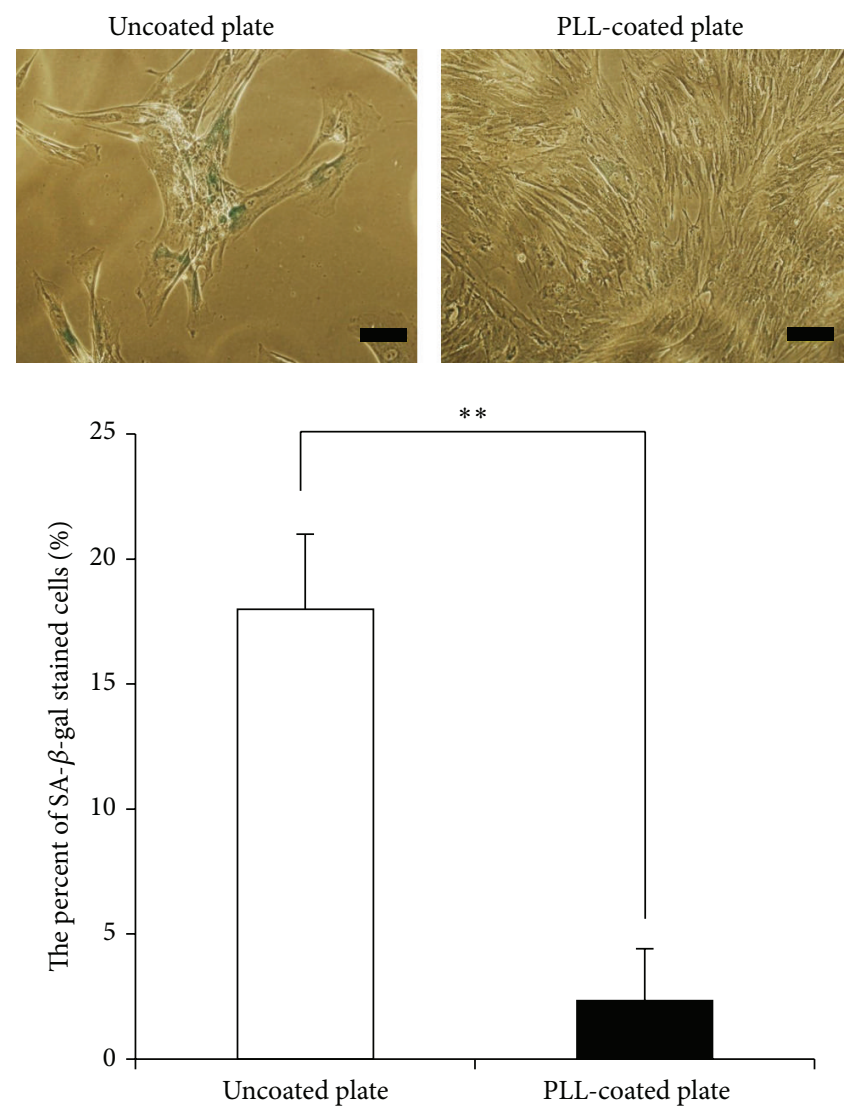

(c)

FIGURE 2: Changes in senescent cells induced by extracellular matrix (ECM) coating. (a) Morphological changes and population doubling time in senescent cells cultivated on a poly-L-lysine- (PLL-) coated plate were observed compared to cells cultured on an uncoated plate (magnification: 100x, scale bar $=200 \mu \mathrm{m}$ ). (b) Cell cycle analysis. Cells were removed from the culture well, stained for DNA with propidium iodide (PI), and analysed by flow cytometry. (c) Senescence associated $\beta$-gal assay of MSCs cultured on uncoated and PLL-coated plates. One representative of three independent experiments is shown. The number of $\beta$-gal positive cells was enumerated. The data represent the mean \pm standard deviation of three experiments (magnification: 200x, scale bar $=100 \mu \mathrm{m}$ ). ${ }^{* *} p<0.01$.

cell culture condition, in which MSCs were grown on plates coated with PLL, which is known to promote cell adhesion to solid substrates and to recreate the in vivo microenvironment. We observed an increase in the number of MSCs cultured on PLL-coated plates with activation of the S-phase of the cell cycle. These results indicate the positive effects of PLL on the proliferation of MSCs in in vitro culture. In addition, PLL retarded MSC replicative senescence, as determined by $\beta$-galactosidase staining, demonstrating that PLL-coated plates provide the necessary microenvironment for optimal growth of MSCs in vitro. Interestingly, CD73, ecto- $5^{\prime}$-nucleotidase used as a marker for MSCs, was rarely 


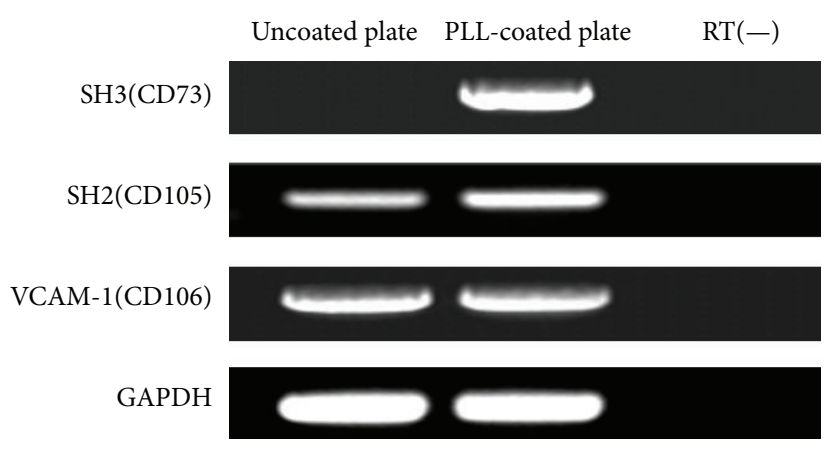

(a)

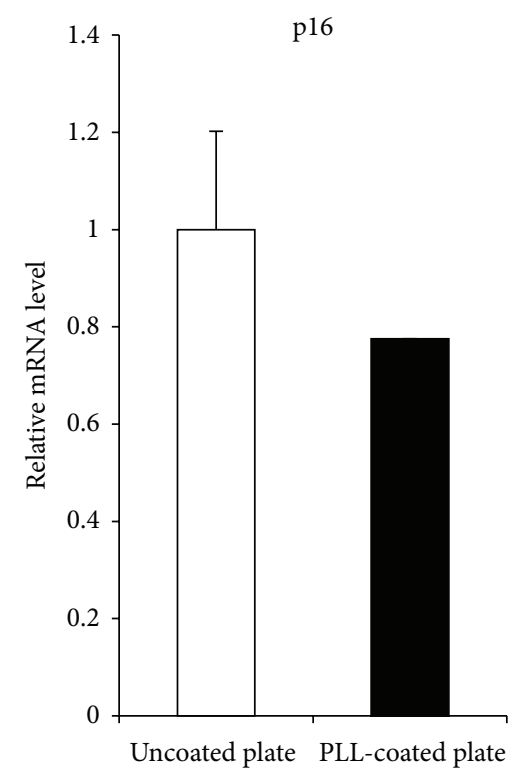

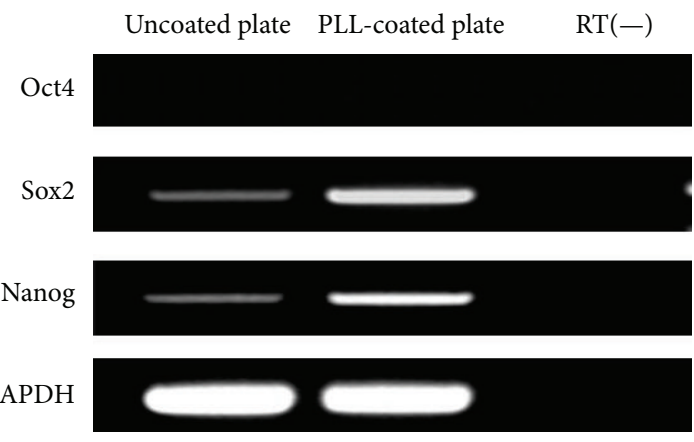

(b)

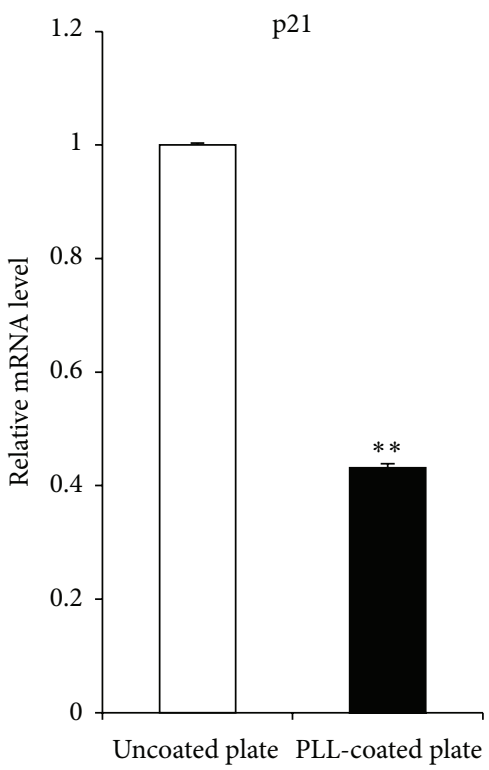

(c)

FIGURE 3: Gene expression of cells cultured on uncoated and poly-L-lysine- (PLL-) coated plates. Gene expression was analysed by RT-PCR for (a) MSC and (b) stemness markers. (c) p16 ${ }^{\text {INK4a }}$ and p $21^{\text {Cip1 }}$ mRNA expression levels were evaluated using RT-PCR. Expression level relative to that of housekeeping gene GAPDH is shown. ${ }^{* *} p<0.01$.

expressed in senescent MSCs, whereas MSCs cultured on PLL-coated plates strongly expressed this marker. It is known that most cells that express CD73 are responsible for the production of extracellular adenosine; however its specific function in MSCs is not fully understood. CD73 may be associated with replicative senescence and be a marker of MSC senescence as indicated by our findings (Figure 3(a)). Oct4, Sox2, and Nanog, which are known pluripotency and stemness markers, are very important for self-renewal of stem cells, and they play an essential role in generating induced pluripotent stem cells [54]. Sox2 is also recently known that it is important in maintenance of cell proliferation and multipotency of MSC [55]. Normally, Oct4 that is a key transcription factor essential for survival and self-renewal is expressed in adult stem cells. However, the expression of Oct4 easily disappears during culture in vitro [56]. Oct4 was in our study undetectable because genes concerning pluripotency including Oct4, Sox2, and Nanog were analysed in passage 7 MSCs. Our results demonstrated that Sox2 and Nanog are significantly upregulated in MSCs cultured on PLL-coated plates compared with MSCs cultured on uncoated plates. Upregulation of those stemness factors may play a crucial role in increasing MSC proliferation and delaying replicative senescence of MSCs. Moreover, our results suggest that PLL can significantly improve osteogenic differentiation of MSCs. MSCs could not ordinarily differentiate into osteocytes due to cell aggregation and inhibition of proliferation in osteogenic induction environment. However, PLL had no effect on the adipogenic and chondrogenic differentiation capacity of MSCs.

In this study, we present for the first time an analysis of the global gene expression profiles of senescent MSCs cultured on uncoated versus PLL-coated plates, using human genome microarray to gain insight into the molecular characteristics of senescence. Functional classification of differentially expressed genes, according to the Gene Ontology (GO), demonstrated that genes associated with the cell cycle (GO:0007049), cell division (GO:0051301), cell proliferation (GO:0008283), transcription factor activity (GO:0003700), extracellular region (GO:0005576), positive 


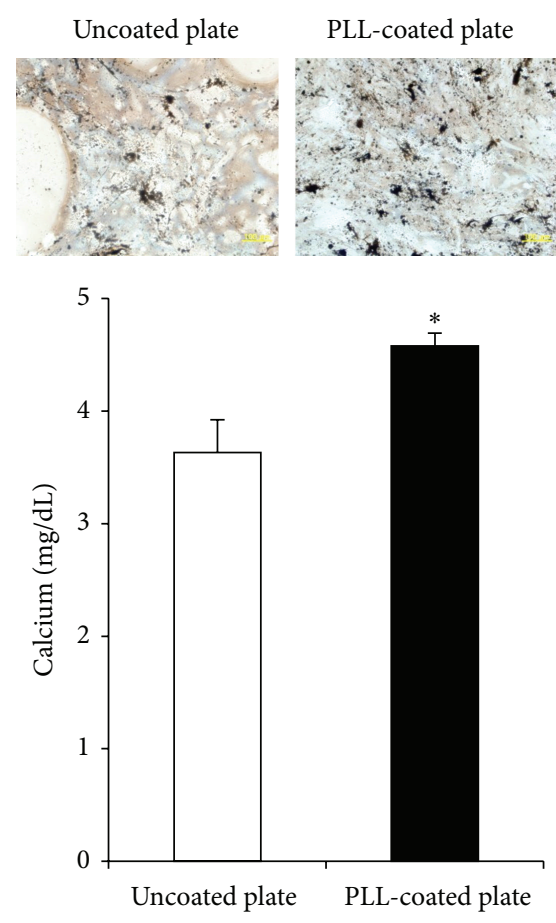

(a)
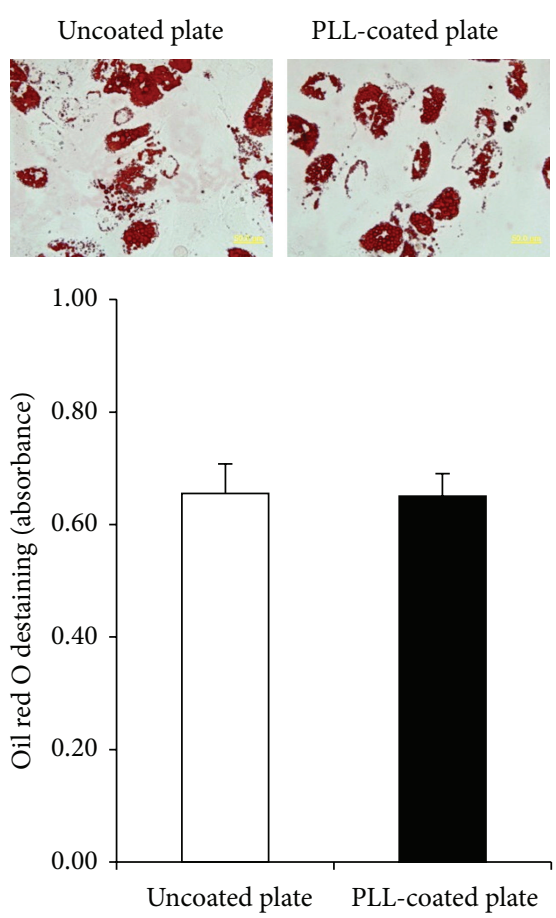

(b)
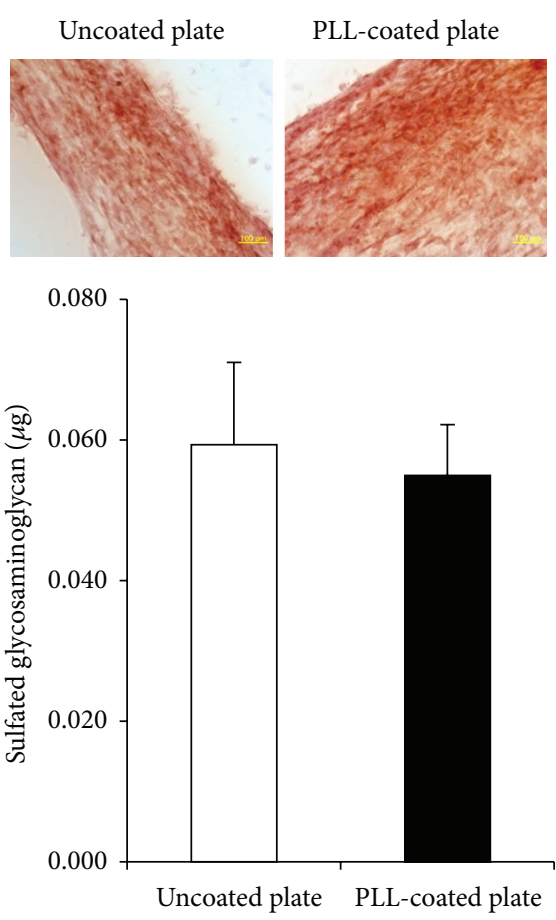

(c)

FIGURE 4: Differentiation potential of cells cultured on uncoated and poly-L-lysine- (PLL-) coated plates. (a) Osteogenesis was determined by Von Kossa staining and calcium quantification. (b) Adipogenesis was examined by oil red $\mathrm{O}$ staining. For quantitative analysis, absorbance was detected after destaining. (c) Chondrogenesis was analysed by safranin $\mathrm{O}$ staining and glycosaminoglycan quantification. The data represent the mean \pm standard deviation of three independent experiments. ${ }^{*} p<0.05$.

regulation of cell proliferation (GO:0008284), and focal adhesion (GO:0005925) were upregulated in MSCs cultured on PLL-coated plates compared to MSCs cultured on uncoated plates. These findings are in line with the increased proliferation potential of MSCs cultured on PLL-coated plates. Several genes related to cell proliferation might also act as inhibitors of MSC senescence. However, to determine the role of individual genes on MSC, additional studies will be required.

Several studies have reported that MSCs undergo a typical phenomenon of replicative senescence with changing cell morphology and decreasing proliferation under in vitro culture. We determined that senescence of bone marrowderived MSCs occurred after 6 passages. Such senescence is considered to be associated with the accumulation of intracellular reactive oxygen species (ROS) and shortening of telomere length [57]. High levels of ROS are associated with the loss of stemness, and growth arrest is triggered by the p53 and p21 pathways $[58,59]$. In this study, we showed that the cell senescence was inhibited by PLL through the suppression of $\mathrm{p} 16^{\mathrm{INK} 4 \mathrm{a}}$ and $\mathrm{p} 21^{\mathrm{Cip} 1} \mathrm{mRNA}$ expression levels. Based on those mechanisms, it was recently reported that cellular senescence of MSCs could be inhibited via FGF2 mediated suppression of p53 and p21 [60]. Overall, our study showed that PLL induces the upregulation of genes involved in cell adhesion, FGF-2 signalling, cell cycle regulation, stemness, cell differentiation, and cell proliferation with downregulation of genes associated with oxidative stress and tumorigenicity. Changes in those genes corresponded to significant suppression of MSC senescence by PLL. The genes affected by PLL are summarized in Tables 2 and 3. Our results require further investigation as to the specific genes that have functional implications on senescent MSCs.

Cellular senescence is generally considered an irreversible cellular change. In our study, the proliferation capacity and functionality of senescent MSCs were improved by PLL; however this effect of PLL was reversed when these cells were recultured in the absence of PLL on uncoated plates (data not shown). PLL as a coating substrate affects senescent MSCs when the cells attached on PLL through cell to ECM interaction. Therefore, senescent MSCs on uncoated plates could return to a senescence phenotype if they were not maintained on PLL-coated culture vessels. Previously, Yocum et al. reported that infusing cells labeled with ferumoxidesPLL complex does not affect hematologic or biochemical measures [61]. MSCs cultured on and mixed with PLL may be useful for clinical application because PLL definitely enhances functionality, and it does not alter biochemical and hematologic measurements in vivo.

In conclusion, we established an easy and simple culture system for culturing MSCs. Our system enhanced the proliferation rates of MSCs and evokes consistent changes in gene expression associated with MSC stemness markers and differentiation potential. We conclude that senescent MSCs can 
be converted to a normal-like state using PLL. Improvement of the MSC culture system in vitro will contribute greatly to the development of cell-based therapy and regenerative medicine.

\section{Competing Interests}

The authors declare that there is no conflict of interests regarding the publication of this paper.

\section{Acknowledgments}

This research was supported by Basic Science Research Program through the National Research Foundation of Korea (NRF) funded by the Ministry of Education (2013R1A1A2061722) and Grant HI15C0942 from the Korea Health Technology R\&D Project through the Korea Health Industry Development Institute (KHIDI), funded by the Ministry of Health \& Welfare, Republic of Korea.

\section{References}

[1] M. F. Pittenger, A. M. Mackay, S. C. Beck et al., "Multilineage potential of adult human mesenchymal stem cells," Science, vol. 284, no. 5411, pp. 143-147, 1999.

[2] S. A. Wexler, C. Donaldson, P. Denning-Kendall, C. Rice, B. Bradley, and J. M. Hows, "Adult bone marrow is a rich source of human mesenchymal 'stem' cells but umbilical cord and mobilized adult blood are not," British Journal of Haematology, vol. 121, no. 2, pp. 368-374, 2003.

[3] G. Kögler, S. Sensken, and P. Wernet, "Comparative generation and characterization of pluripotent unrestricted somatic stem cells with mesenchymal stem cells from human cord blood," Experimental Hematology, vol. 34, no. 11, pp. 1589-1595, 2006.

[4] S. Barlow, G. Brooke, K. Chatterjee et al., "Comparison of human placenta- and bone marrow-derived multipotent mesenchymal stem cells," Stem Cells and Development, vol. 17, no. 6, pp. 1095-1107, 2008.

[5] H. Busser, C. De Bruyn, F. Urbain et al., "fIsolation of adiposederived stromal cells without enzymatic treatment: expansion, phenotypical, and functional characterization," Stem Cells and Development, vol. 23, no. 19, pp. 2390-2400, 2014.

[6] P. H. Lee, J. E. Lee, H.-S. Kim et al., "A randomized trial of mesenchymal stem cells in multiple system atrophy," Annals of Neurology, vol. 72, no. 1, pp. 32-40, 2012.

[7] L. Mazzini, K. Mareschi, I. Ferrero et al., "Autologous mesenchymal stem cells: clinical applications in amyotrophic lateral sclerosis," Neurological Research, vol. 28, no. 5, pp. 523-526, 2006.

[8] W. Wagner, P. Horn, M. Castoldi et al., "Replicative senescence of mesenchymal stem cells: a continuous and organized process," PLoS ONE, vol. 3, no. 5, Article ID e2213, 2008.

[9] L. Hayflick, “The limited in vitro lifetime of human diploid cell strains," Experimental Cell Research, vol. 37, no. 3, pp. 614-636, 1965.

[10] M. M. Bonab, K. Alimoghaddam, F. Talebian, S. H. Ghaffari, A. Ghavamzadeh, and B. Nikbin, "Aging of mesenchymal stem cell in vitro," BMC Cell Biology, vol. 7, article 14, 2006.
[11] K. Itahana, J. Campisi, and G. P. Dimri, "Mechanisms of cellular senescence in human and mouse cells," Biogerontology, vol. 5, no. 1, pp. 1-10, 2004.

[12] S. Loft, P. H. Danielsen, L. Mikkelsen, L. Risom, L. Forchhammer, and P. Møller, "Biomarkers of oxidative damage to DNA and repair," Biochemical Society Transactions, vol. 36, no. 5, pp. 1071-1076, 2008.

[13] W. L. Grayson, F. Zhao, B. Bunnell, and T. Ma, "Hypoxia enhances proliferation and tissue formation of human mesenchymal stem cells," Biochemical and Biophysical Research Communications, vol. 358, no. 3, pp. 948-953, 2007.

[14] W. L. Grayson, F. Zhao, R. Izadpanah, B. Bunnell, and T. Ma, "Effects of hypoxia on human mesenchymal stem cell expansion and plasticity in 3D constructs," Journal of Cellular Physiology, vol. 207, no. 2, pp. 331-339, 2006.

[15] H. Ren, Y. Cao, Q. Zhao et al., "Proliferation and differentiation of bone marrow stromal cells under hypoxic conditions," Biochemical and Biophysical Research Communications, vol. 347, no. 1, pp. 12-21, 2006.

[16] K. R. Shibata, T. Aoyama, Y. Shima et al., "Expression of the p16INK4A gene is associated closely with senescence of human mesenchymal stem cells and is potentially silenced by DNA methylation during in vitro expansion," STEM CELLS, vol. 25, no. 9, pp. 2371-2382, 2007.

[17] M. Abedin and N. King, "Diverse evolutionary paths to cell adhesion," Trends in Cell Biology, vol. 20, no. 12, pp. 734-742, 2010.

[18] G. Michel, T. Tonon, D. Scornet, J. M. Cock, and B. Kloareg, "The cell wall polysaccharide metabolism of the brown alga Ectocarpus siliculosus. Insights into the evolution of extracellular matrix polysaccharides in Eukaryotes," New Phytologist, vol. 188, no. 1, pp. 82-97, 2010.

[19] B. de Kruijff and P. R. Cullis, "The influence of poly(Llysine) on phospholipid polymorphism. Evidence that electrostatic polypeptide-phospholipid interactions can modulate bilayer/non-bilayer transitions," Biochimica et Biophysica Acta, vol. 601, no. 1, pp. 235-240, 1980.

[20] K. Pachmann and W. Leibold, "Insolubilization of protein antigens on polyacrylic plastic beads using poly-l-lysine," Journal of Immunological Methods, vol. 12, no. 1-2, pp. 81-89, 1976.

[21] K.-S. Park, J. Ahn, J. Y. Kim, H. Park, H. O. Kim, and S.-H. Lee, "Poly-L-lysine increases the ex vivo expansion and erythroid differentiation of human hematopoietic stem cells, as well as erythroid enucleation efficacy," Tissue Engineering Part A, vol. 20, no. 5-6, pp. 1072-1080, 2014.

[22] L. Cai, J. Lu, V. Sheen, and S. Wang, "Optimal poly(l-lysine) grafting density in hydrogels for promoting neural progenitor cell functions," Biomacromolecules, vol. 13, no. 5, pp. 1663-1674, 2012.

[23] A. I. Caplan and D. Correa, “The MSC: an injury drugstore," Cell Stem Cell, vol. 9, no. 1, pp. 11-15, 2011.

[24] P. Charbord, "Bone marrow mesenchymal stem cells: historical overview and concepts," Human Gene Therapy, vol. 21, no. 9, pp. 1045-1056, 2010.

[25] H.-S. Kim, D.-Y. Choi, S. J. Yun et al., "Proteomic analysis of microvesicles derived from human mesenchymal stem cells," Journal of Proteome Research, vol. 11, no. 2, pp. 839-849, 2012.

[26] M. S. Choudhery, M. Khan, R. Mahmood, A. Mehmood, S. N. Khan, and S. Riazuddin, "Bone marrow derived mesenchymal stem cells from aged mice have reduced wound healing, angiogenesis, proliferation and anti-apoptosis capabilities," Cell Biology International, vol. 36, no. 8, pp. 747-753, 2012. 
[27] Y. H. Kim, D. S. Yoon, H. O. Kim, and J. W. Lee, "Characterization of different subpopulations from bone marrow-derived mesenchymal stromal cells by alkaline phosphatase expression," Stem Cells and Development, vol. 21, no. 16, pp. 2958-2968, 2012.

[28] L.-X. Tay, C.-K. Lim, A. Mansor, and T. Kamarul, "Differential protein expression between chondrogenic differentiated MSCs, undifferentiated MSCs and adult chondroctyes derived from Oryctolagus cuniculus in vitro," International Journal of Medical Sciences, vol. 11, no. 1, pp. 24-33, 2013.

[29] E. Pierantozzi, B. Gava, I. Manini et al., "Pluripotency regulators in human mesenchymal stem cells: expression of NANOG but not of OCT-4 and SOX-2," Stem Cells and Development, vol. 20, no. 5, pp. 915-923, 2011.

[30] C.-C. Tsai, P.-F. Su, Y.-F. Huang, T.-L. Yew, and S.-C. Hung, "Oct4 and nanog directly regulate Dnmtl to maintain selfrenewal and undifferentiated state in mesenchymal stem cells," Molecular Cell, vol. 47, no. 2, pp. 169-182, 2012.

[31] J. Ge, Y. Ju, Z. Xue et al., "Distal C terminus of CaV1.2 channels plays a crucial role in the neural differentiation of dental pulp stem cells," PLoS ONE, vol. 8, no. 11, Article ID e81332, 2013.

[32] M.-L. Nueda, V. Baladrón, J.-J. García-Ramírez et al., “The novel gene EGFL9/Dlk2, highly homologous to Dlk1, functions as a modulator of adipogenesis," Journal of Molecular Biology, vol. 367, no. 5, pp. 1270-1280, 2007.

[33] C. Hoareau-Aveilla, M. Bonoli, M. Caizergues-Ferrer, and Y. Henry, "hNafl is required for accumulation of human box H/ACA snoRNPs, scaRNPs, and telomerase," RNA, vol. 12, no. 5, pp. 832-840, 2006.

[34] S.-T. Liu, J. C. Hittle, S. A. Jablonski, M. S. Campbell, K. Yoda, and T. J. Yen, "Human CENP-I specifies localization of CENP-F, MAD1 and MAD2 to kinetochores and is essential for mitosis," Nature Cell Biology, vol. 5, no. 4, pp. 341-345, 2003.

[35] A. Than, X. Zhang, M. K.-S. Leow, C. L. Poh, S. K. Chong, and P. Chen, "Apelin attenuates oxidative stress in human adipocytes," The Journal of Biological Chemistry, vol. 289, no. 6, pp. 37633774, 2014.

[36] H. Shao, J. H. Wang, M. R. Pollak, and A. Wells, " $\alpha$-actinin4 is essential for maintaining the spreading, motility and contractility of fibroblasts," PLoS ONE, vol. 5, no. 11, Article ID e13921, 2010.

[37] M.-Y. Lee, H.-D. Hofmann, and M. Kirsch, "Expression of ciliary neurotrophic factor receptor- $\alpha$ messenger RNA in neonatal and adult rat brain: an in situ hybridization study," Neuroscience, vol. 77, no. 1, pp. 233-246, 1997.

[38] M. Yasumi, T. Sakisaka, T. Hoshino et al., "Direct binding of Lgl2 to LGN during mitosis and its requirement for normal cell division," Journal of Biological Chemistry, vol. 280, no. 8, pp. 6761-6765, 2005.

[39] J. Christensen, P. Cloos, U. Toftegaard et al., "Characterization of E2F8, a novel E2F-like cell-cycle regulated repressor of E2Factivated transcription," Nucleic Acids Research, vol. 33, no. 17, pp. 5458-5470, 2005.

[40] E. Manser, T. Leung, H. Salihuddin, L. Tan, and L. Lim, "A non-receptor tyrosine kinase that inhibits the GTPase activity of p21cdc42," Nature, vol. 363, no. 6427, pp. 364-367, 1993.

[41] S. Diecke, A. Quiroga-Negreira, T. Redmer, and D. Besser, "FGF2 signaling in mouse embryonic fibroblasts is crucial for self-renewal of embryonic stem cells," Cells Tissues Organs, vol. 188, no. 1-2, pp. 52-61, 2008.

[42] R. Nakayama, Y. Miura, J. Ogino et al., "Detection of HEY1-NCOA2 fusion by fluorescence in-situ hybridization in formalin-fixed paraffin-embedded tissues as a possible diagnostic tool for mesenchymal chondrosarcoma," Pathology International, vol. 62, no. 12, pp. 823-826, 2012.

[43] S. Goicoechea, A. W. Orr, M. A. Pallero, P. Eggleton, and J. E. Murphy-Ullrich, "Thrombospondin mediates focal adhesion disassembly through interactions with cell surface calreticulin," The Journal of Biological Chemistry, vol. 275, no. 46, pp. 3635836368, 2000.

[44] T. Kim, K. Kim, S. H. Lee et al., "Identification of LRRc17 as a negative regulator of receptor activator of NF- $\kappa B$ ligand (RANKL)-induced osteoclast differentiation," Journal of Biological Chemistry, vol. 284, no. 22, pp. 15308-15316, 2009.

[45] H. Yoshioka and F. Ramirez, "Pro-alpha 1(XI) collagen. Structure of the amino-terminal propeptide and expression of the gene in tumor cell lines," The Journal of Biological Chemistry, vol. 265, no. 11, pp. 6423-6426, 1990.

[46] L. Zhang, M. Wang, X. Kang et al., "Oxidative stress and asthma: proteome analysis of chitinase-like proteins and FIZZ1 in lung tissue and bronchoalveolar lavage fluid," Journal of Proteome Research, vol. 8, no. 4, pp. 1631-1638, 2009.

[47] A. Khurana, H. McKean, H. Kim et al., "Silencing of HSulf2 expression in MCF10DCIS.com cells attenuate ductal carcinoma in situ progression to invasive ductal carcinoma in vivo," Breast Cancer Research, vol. 14, no. 2, article R43, 2012.

[48] M. Morimoto-Tomita, K. Uchimura, A. Bistrup et al., "Sulf-2, a proangiogenic heparan sulfate endosulfatase, is upregulated in breast cancer," Neoplasia, vol. 7, no. 11, pp. 1001-1010, 2005.

[49] A. W. Orr, M. A. Pallero, and J. E. Murphy-Ullrich, “Thrombospondin stimulates focal adhesion disassembly through Giand phosphoinositide 3-kinase-dependent ERK activation," Journal of Biological Chemistry, vol. 277, no. 23, pp. 2045320460, 2002.

[50] K. Tanaka, Y. Okugawa, Y. Toiyama et al., "Brain-Derived Neurotrophic Factor (BDNF)-induced Tropomyosin-related kinase B (Trk B) signaling is a potential therapeutic target for peritoneal carcinomatosis arising from colorectal cancer," PLOS ONE, vol. 9, no. 5, article e96410, 2014.

[51] J. You, D. S. Shin, D. Patel, Y. Gao, and A. Revzin, "Multilayered heparin hydrogel microwells for cultivation of primary hepatocytes," Advanced Healthcare Materials, vol. 3, no. 1, pp. 126-132, 2014.

[52] Y. Xu, X. Zhu, H. S. Hahm et al., "Revealing a core signaling regulatory mechanism for pluripotent stem cell survival and self-renewal by small molecules," Proceedings of the National Academy of Sciences of the United States of America, vol. 107, no. 18, pp. 8129-8134, 2010.

[53] N. Z. Kuhn and R. S. Tuan, "Regulation of stemness and stem cell niche of mesenchymal stem cells: Implications in tumorigenesis and metastasis," Journal of Cellular Physiology, vol. 222, no. 2, pp. 268-277, 2010.

[54] D. J. Rodda, J.-L. Chew, L.-H. Lim et al., "Transcriptional regulation of Nanog by OCT4 and SOX2," Journal of Biological Chemistry, vol. 280, no. 26, pp. 24731-24737, 2005.

[55] D. S. Yoon, Y. H. Kim, H. S. Jung, S. Paik, and J. W. Lee, "Importance of Sox2 in maintenance of cell proliferation and multipotency of mesenchymal stem cells in low-density culture," Cell Proliferation, vol. 44, no. 5, pp. 428-440, 2011.

[56] T. M. Liu, Y. N. Wu, X. M. Guo, J. H. P. Hui, E. H. Lee, and B. Lim, "Effects of Ectopic Nanog and Oct4 overexpression on mesenchymal stem cells," Stem Cells and Development, vol. 18, no. 7, pp. 1013-1022, 2009. 
[57] K. Ksiazek, "A comprehensive review on mesenchymal stem cell growth and senescence," Rejuvenation Research, vol. 12, no. 2, pp. 105-116, 2009.

[58] U. Herbig, W. A. Jobling, B. P. C. Chen, D. J. Chen, and J. M. Sedivy, "Telomere shortening triggers senescence of human cells through a pathway involving ATM, p53, and p21CIP1, but not p16INK4a," Molecular Cell, vol. 14, no. 4, pp. 501-513, 2004.

[59] Z. Tothova, R. Kollipara, B. J. Huntly et al., "FoxOs are critical mediators of hematopoietic stem cell resistance to physiologic oxidative stress," Cell, vol. 128, no. 2, pp. 325-339, 2007.

[60] T. Ito, R. Sawada, Y. Fujiwara, Y. Seyama, and T. Tsuchiya, "FGF-2 suppresses cellular senescence of human mesenchymal stem cells by down-regulation of TGF- $\beta 2$," Biochemical and Biophysical Research Communications, vol. 359, no. 1, pp. 108114, 2007.

[61] G. T. Yocum, L. B. Wilson, P. Ashari, E. K. Jordan, J. A. Frank, and A. S. Arbab, "Effect of human stem cells labeled with ferumoxides-poly-L-lysine on hematologic and biochemical measurements in rats," Radiology, vol. 235, no. 2, pp. 547-552, 2005. 

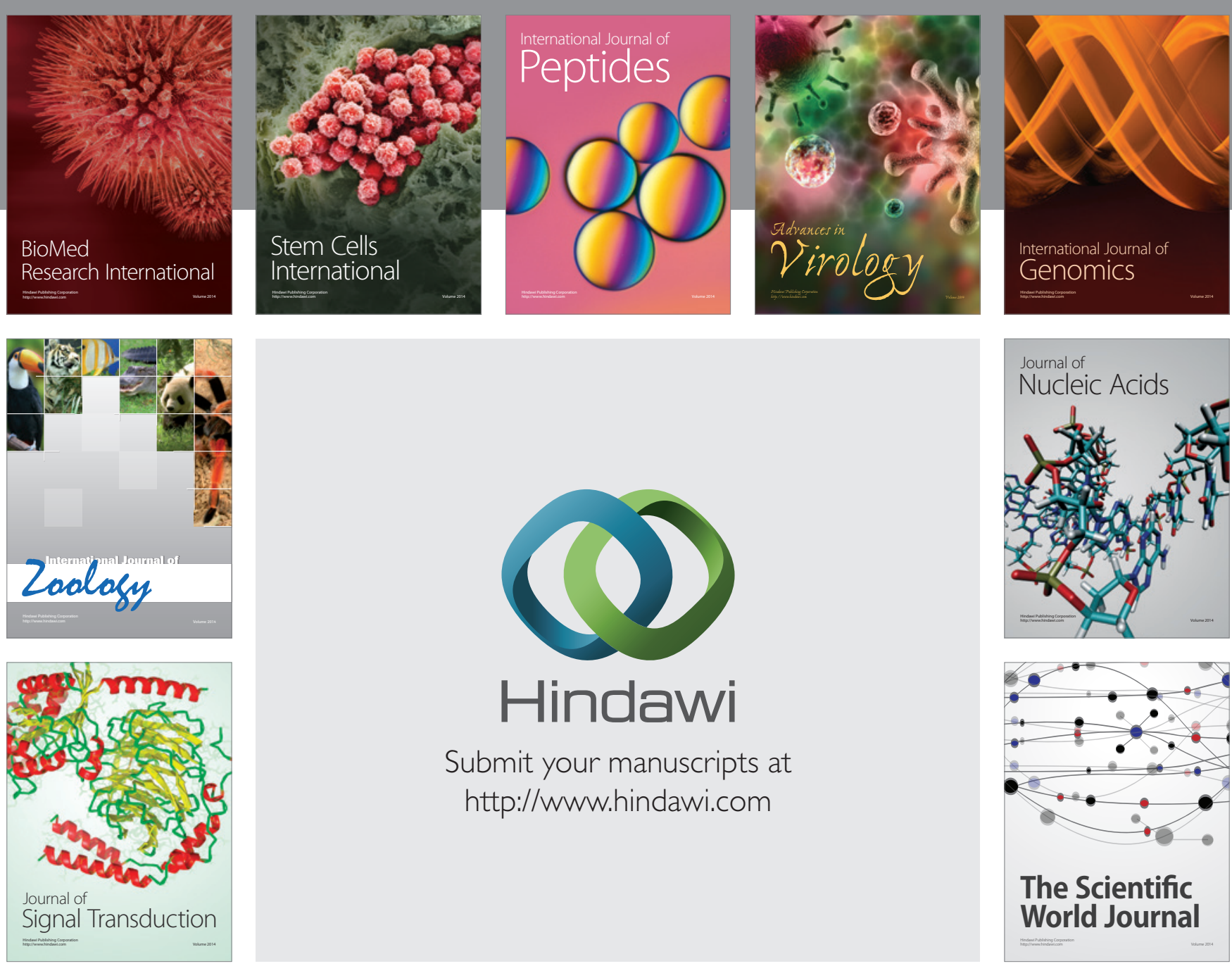

Submit your manuscripts at

http://www.hindawi.com
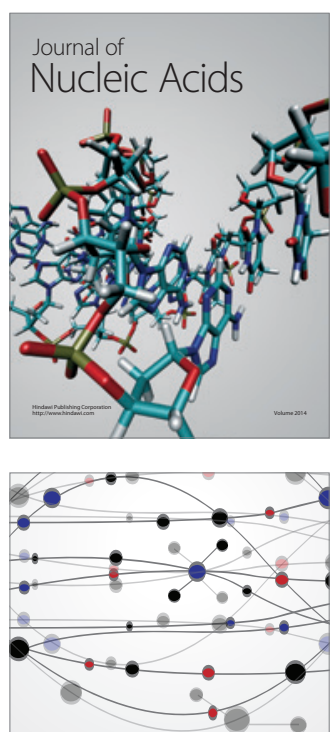

The Scientific World Journal
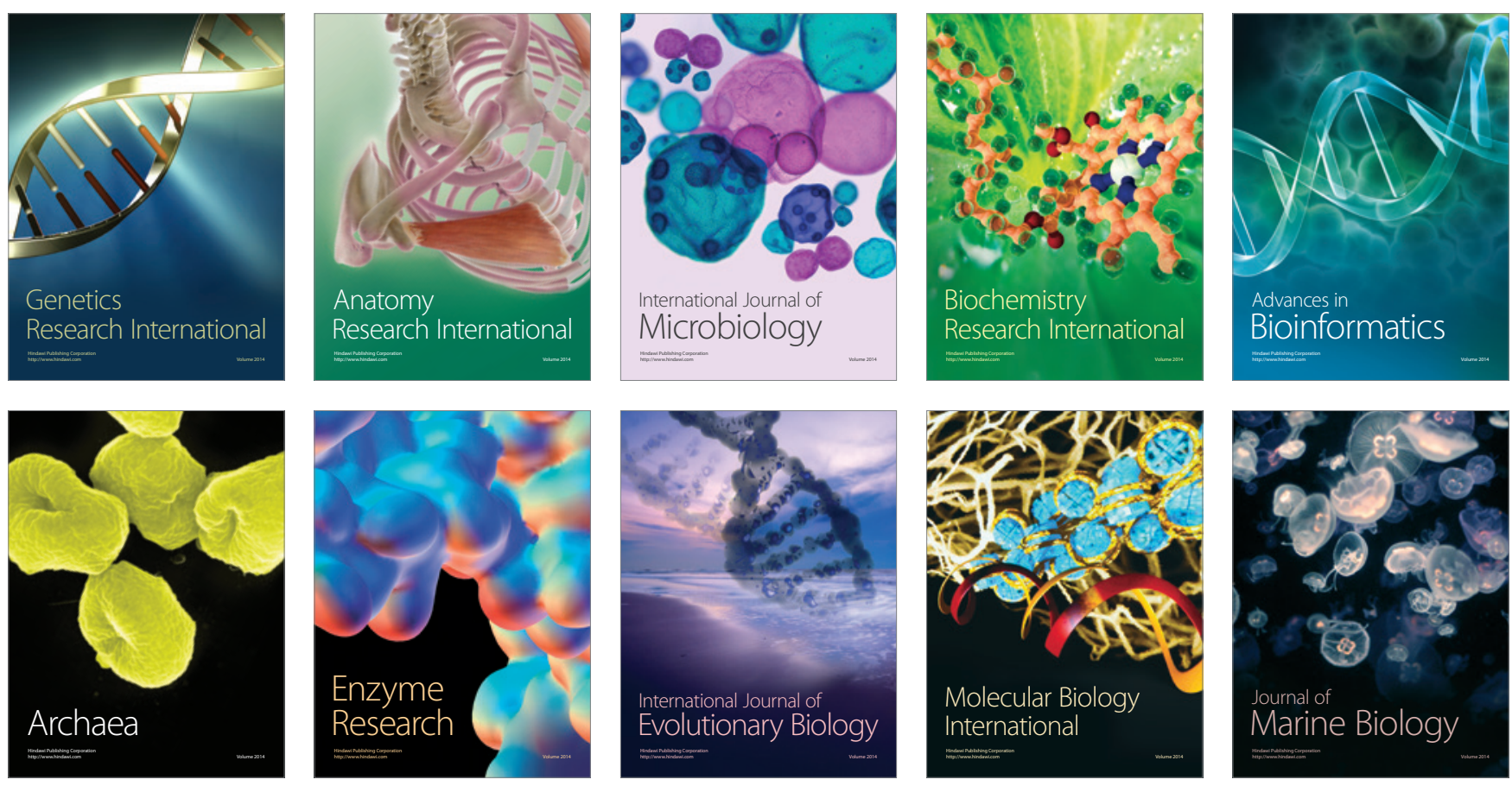